\title{
The Relationship between Rehabilitation of Severe Early Childhood Caries and Well-Being in 5 Years Old Patient, A Case Report
}

\author{
Chaza Kouchaji ${ }^{1 *}$ and Asmaa Sayed Sulayman ${ }^{2}$ \\ ${ }^{1}$ Head of Syrian pedodontic association, Prof of Pedodontic department, Faculty of dental medicine, Damascus university, Syria \\ ${ }^{2}$ Master pedodontics student, Pedodontic department, Faculty of dental medicine, Damascus university, Syria
}

*Corresponding author: Chaza Kouchaji, Head of Syrian pedodontic association, Prof of
Pedodontic department, Faculty of dental medicine, Damascus university, Syria.
Received Date: January 08, 2021

Published Date: February 02, 2021

\begin{abstract}
Early Childhood Caries (ECC) is a public health problem that continues to affect infants and preschool children worldwide, and severe destruction of primary teeth due to caries is a common occurrence in children under 6-years-old. The purpose of this report was to present a case of a 5-yearold patient with severe ECC and the effect of mouth rehabilitation on child's lifestyle. In this case a comprehensive treatment plan was followed, including many types of procedures to achieve functional requirements which have important role in nutrition and proper development in this age.

Keywords: Early childhood caries; Rehabilitation; Comprehensive treatment; Well-being
\end{abstract}

\section{Introduction}

ECC experience is defined as the presence of one or more decayed (noncavitated or cavitated lesions), missing (due to caries) or filled tooth surfaces in any primary tooth in a child aged 71 months or younger [1]. ECC is the most commonly observed chronic disease in children [2]. ECC continues to be pandemic disease according to World Health Organization. The prevalence generally ranges from $27 \%-48 \%$, with more than $76 \%$ reported from the Middle East [3]. While in Syria the burden of ECC amongst Syrian children aged 3-5 years was dmft value of $4.25 \pm 4.2$ per child [4]. Main risk factors that contribute to the formation of ECC were microbiological, environmental and dietary factors [5].

The clinical appearance of the teeth in S-ECC in a child 2, 3, or 4 years of age is typical and follows a definite pattern. There is early carious involvement of the maxillary anterior teeth, the maxillary and mandibular first primary molars, and sometimes the mandibular canines [6]. Sharna, et al. [7] reported many responses related to ECC which include Pain and problem in drinking, eating, sleeping, and talking [7].

\section{Case Description}

A 5-year-old female child was brought to the Pediatric Dentistry Clinic, Damascus University, Damascus, Syria. According to medical history, the patient suffered from repeated respiratory infections and mother mentioned that her family had been internally displaced during Syrian crisis. According to dental history, the mother reported that there were several visits to general dentists ended up without any treatment and the chief complaint as mother reported was that teeth were darkened with inability to eat or smile properly. Patient behavior was hesitant according to Frankl Behavior Rating Scale modified by Salviov-Tinawi. By clinical examination, there were several caries ranging from white spot lesions to cavitated lesions with pulp involvement. 


\section{Treatment}

First of all, preventive procedure was explained to mother in order to enhance oral hygiene. Basic behavior management techniques were used. In first session, Tell-Show-Do technique was used to increase patient acceptance for treatment. In later sessions the control on patient behavior was lost, starting refuse to cooperate so parents were separated till the patient return to cooperate status. Different techniques were used along sessions and the treatment ends up and the patient and her parents were satisfied.
Pulpotomy had been achieved in 54-55-65-84-85 and stainlesssteel crowns as final restorations. pulpectomy had been achieved in 75 with indirect resin composite crown as a final restoration. Restorative treatment with resin composite in 53-63-73-72-71-8182-83. Space maintainer (band and loop) had been achieved after extraction of 64-74 and 52-51-61-62 extracted (severely decayed) (Figure 1,2). In follow up session patient physical status had improved with more comfortable in eating, sleeping and overall health as care provider reported.
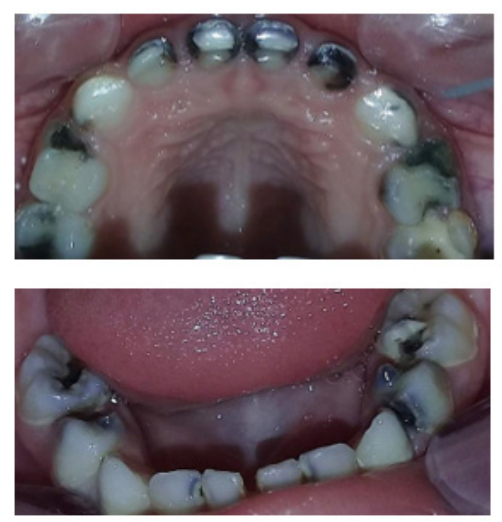

Figure 1: Pre-operative.
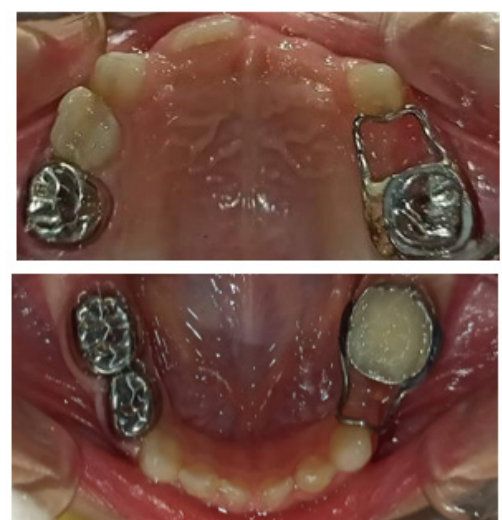

Figure 2: Post-operative.

\section{Discussion}

Different Factors combined and affected each other to arrive this case of sever ECC. The patient and her family were internally displaced during Syrian crisis, Alhaffar, et al. 2019 [8] mentioned in their study about oral health and socio-economic status (SES) among children during Syrian crisis that there was a strong association between SES and oral health [8]. The restoration of primary teeth severely destroyed by ECC is a challenge for pediatric dentists, due to child behavior and age. ECC is associated with a child's overall quality of life, including the ability to eat, speak, and socialize without discomfort. The preventive procedures were first step in treatment plan. In fluoride-deficient communities, the best practice to reduce the risk of ECC includes twice-daily brushing with fluoridated toothpaste with proper brushing technique [9].

Patients with S-ECC usually represent multiple decay teeth at various stages of progression. Some teeth may need restorations while some may need stainless steel crowns with or without pulp therapy, etc. [10]. In this patient case, caries was involving pulp tissues with peri-apical lesion, or slightly near to pulp chamber, and in lower incisors, caries lesion was limited. So, the treatment varies from conservative to extraction and all teeth were restored by crowns. ECC affects child and parents' and the most affected parameters were consumption of food and sleep-in children [11]. The consequences of ECC have huge effect on children's growth, function, and quality of life. and it has been observed that the greater the teeth affected, the greater the negative impact on quality of life 
[12], in reported case whole primary teeth were affected which was cause of recurrent pain.

Li, et al. [13] mentioned in their study in moderately developed region in China about the impact of ECC on quality of life that the parental distress, child function, and child symptoms accounted for the highest prevalence, extent, and severity of impacts. and may the impact be more severe in Syria during last ten years because of crisis' effect on economic situation. Such a condition may affect patient's childhood and self-satisfactory which make it important to prevent dental related problems or seek treatment directly as those conditions emerge.

\section{Acknowledgement}

None.

\section{Conflict of Interest}

No conflict of interest.

\section{References}

1. Evans RW, Feldens CA, Phantunvanit P (2018) A protocol for early childhood caries diagnosis and risk assessment", in Community Dentistry and Oral Epidemiology. Community Dent Oral Epidemiology 46(5): 518-525.

2. Bodrumlu EH, Demiriz L, Toprak S (2018) Relationship between Severe Early Childhood Caries and dental development. Eur J pediatr dent 19(2): 156-160.

3. Seow Wk (2018) Early Childhood Caries. Pediatr Clin N Am 65: 941-954.
4. Qadri Gh, Nourallah A, Splieth ChH (2012) Early childhood caries and feeding practices in kindergarten children. Quintessence Int 43: 503510 .

5. Alazmah A (2017) Early Childhood Caries: A Review. J Contemp Dent Pract 18(8): 732-737.

6. Chin (2016) Dental Caries in the Child and Adolescent" in McDonald and Avery's Dentistry for the Child and Adolescent, Elsevier, ( $10^{\text {th }}$ edn.), Pp: 155-176.

7. Sharna N, Ramakrishnan M, Samuel V, Ravikumar, Cheenglembi Kh, et al. (2019) Association between Early Childhood Caries and Quality of Life Early Childhood Oral Health Impact Scale and Pufa Index. Dent J 7: 95.

8. Alhaffar B, Alawabdi R, Barakat L, Kouchaji Ch (2019) Oral health and socio-economic status among children during Syrian crisis: a crosssectional study. BMC Oral Health 19(1): 165.

9. (2016) American Academy of Pediatric Dentistry, Policy on Early Childhood Caries (ECC): Classifications, Consequences, and Preventive Strategies. Oral Health Policies.

10. Muthu MS, Sivakumar N (2011) Early childhood Caries in Pediatric Dentistry principles and practice (2 ${ }^{\text {nd }}$ Edn.), Elsevier Pp:595-619.

11. Acharya S, Tandon S (2011) The effect of early childhood caries on the quality of life of children and their parents. Contemp Clin Dent 2(2): 98101.

12. Bonecker M, Abanto J, Tello G, Oliveira LB (2012) Impact of dental caries on preschool children's quality of life: an update. Braz Oral Res 26: 103107.

13. Li MY, Zhi QH, Qiu R M, Lin HC (2015) Impact of Early Childhood Caries on oral health-related quality of life of preschool children. Eur J Paediatr Dent 16: 65-72. 